Thematic Article

\title{
Introductory Survey on Challenges Encountered by University Teachers in Online Teaching of STEM Subjects During COVID-19 Lockdown
}

\author{
Elena Hadzieva ${ }^{1}$, Ján Gunčaga ${ }^{2}$, Subash Chandra Bose ${ }^{3}$, Kalina Sotiroska Ivanoska ${ }^{4}$ \\ Recommended citation: \\ Hadzieva, E., Gunčaga, J., Bose, S. C., \& Ivanoska, K. S. (2021). Introductory survey on challenges encountered by \\ university teachers in online teaching of STEM subjects during COVID-19 lockdown. Central European Journal of \\ Educational Research, 3(3), 22-32. https://doi.org/10.37441/cejer/2021/3/3/9601
}

\begin{abstract}
2020 will be remembered for COVID-19, a pandemic that forced the world to lock down and urged most educational providers to promptly implement e-learning solutions. In this paper, we point out some challenges faced by university teachers who had almost no earlier practice in online teaching. Nine lecturers working in different universities from Brazil, the Czech Republic, Estonia, Hungary, India, Macedonia, and Slovakia all teaching science, technology, engineering, and mathematics (STEM) subjects - were interviewed to share their online teaching experiences during the COVID-19 lockdown. The aim of this introductory small-scale research paper is to provide a basis for future research regarding the influences that the COVID-19 situation has had on educational processes, as well as to assist educational providers in foreseeing and eliminating the possible problems of lecturers when establishing an online educational environment. Some conclusions are formulated from the interview survey, and possibilities for further research are described.
\end{abstract}

Keywords: COVID-19 lockdown; STEM education; online teaching

\section{Introduction}

In this paper, distance learning is defined as learning without physical presence in the classroom, which nowadays aligns with e-learning (or online learning). Since approximately 20 years ago, "thousands of online courses, including degree and certificate programs, are offered by universities worldwide" (Zhang et al., 2004: 76). In the same paper, Zhang et al. (2004) note that e-learning has the following advantages: e-Learning is learner-centred and self-paced, time and location flexible, cost effective, and potentially available for a global audience, and it offers unlimited access to knowledge, as well as its reuse and sharing; however, it also has some disadvantages, including a lack of immediate feedback in asynchronous e-learning; increased preparation time for the instructor; the fact that it is not comfortable for some people; and potentially more frustrating and confusing, causing anxiety. The list of advantages can be expanded to include more reliable learning material prepared by the teacher, compared to the students' written notes in class, while the list of disadvantages can also include a lack of nonverbal communication.

Communication, both verbal and nonverbal, is especially important for science, technology, engineering, and mathematics (STEM) courses compared to social science courses, since understanding of STEM content greatly depends on students' expressions of the level of comprehension of the new material and teachers' responses to these verbal and nonverbal expressions. STEM courses also involve different models, experiments, laboratory activities, and simulations, and they offer students the opportunity to provide original, smart, and

\footnotetext{
${ }^{1}$ Faculty of Information Systems, Visualization, Multimedia and Animation, University of Information Science and Technology “St. Paul the Apostle”-Ohrid, RN Macedonia; elena.hadzieva@uist.edu.mk

${ }^{2}$ Faculty of Education, Comenius University in Bratislava, Slovakia; guncaga@fedu.uniba.sk

${ }^{3}$ Faculty of Applied IT, Machine Intelligence and Robotics, University of Information Science and Technology "St. Paul the Apostle"-Ohrid, RN Macedonia; subash.jaganathan@uist.edu.mk

${ }^{4}$ Faculty of Philosophy, Ss. Cyril and Methodius University in Skopje, RN Macedonia; kalina.sotiroska@ fzf.ukim.edu.mk
} 
lucid answers to exam questions or in class. Moreover, Kommers (2019) has noted that collaborative learning is an important element of STEM education at universities. However, collaboration makes STEM courses less appropriate for the e-learning model (Stando et al., 2012).

With all of its pros and cons, the e-learning model of education is widely accepted by ambitious higher educational institutions that aim to remain current and to meet the delicate needs of students. Nevertheless, the face-to-face model still prevails. According to the U.S. National Center for Educational Statistics (NCES, 2020), in fall $2017,33.7 \%$ of the total number of U.S. students took at least one online course and only half of them took exclusively distant education courses. "While the number of distance programs and courses online continue to grow, the perception of chief academic officers of the acceptance of this learning modality is still relatively small. Only $29.1 \%$ of chief academic officers believe their faculty accepts the value and legitimacy of online education" (Allen et al., 2016: 6). Academia is perhaps the strongest entity in society that still strives to maintain traditional values and cultivate desirable social characteristics of students. The difficulties in introducing distance learning are especially emphasized in developing countries (Bhuasiri et al., 2012), where the investment of money, time, and effort in e-learning is insufficient. According to Renes \& Strange (2011: 209), the "human factor, rather than the technology is often the limiting factor for distance education".

In these circumstances, where few accepted the distance learning modality, the COVID-19 pandemic emerged and caused university closures in most countries (this occurred mainly in March and April 2020; Natresp, 2020). The universities' leadership and bodies decided that the academic year would be exclusively continued through online classes, to align with the restrictive measures acknowledged by the national governments and ministries of education, with full responsibility for providing continuous education of their students in a short time (1-2 weeks). This situation was alarming for universities that until then had not introduced any online course. Our attention is particularly focused on the university teachers of STEM courses due to the previously described specificity of these courses.

\section{The Immediate Transition from Face-to-Face to Online Lectures}

Three groups of issues and challenges related to teaching online courses, in a normal situation, have been noted in the literature (Kebritchi et al., 2017): issues related to learners ("learners' expectations, readiness, identity, and participation in online courses"), issues related to content ("the role of instructors in content development, integration of multimedia in content, role of instructional strategies in content development, and considerations for content development"), and issues related to instructors ("transition from face-to-face to online, communication barriers, time management, and teaching styles"). The last set of issues are particularly sensitive: They require time and teachers' individual human capacity to overcome the mental barrier to shifting from in-person to online education. As expected, senior science educators in general have serious difficulties in this transition (Crawley et al., 2009).

The universities or faculties that decided to continue with online classes due to the COVID-19 restrictions had to instantly make many other decisions, such as the following:

- $\quad$ what distance learning platform(s) to recommend;

- what software to advise for preparing materials, sharing materials or announcements, issuing assignments or projects, and grading;

- whether or not to train educators for distance learning and/or offer pedagogical tips and tricks for successful distance teaching;

- whether, if at all, and how much to invest in software, course development, or hardware (e.g., touchscreen laptops, pen tablets, stylus pens, digital pens, etc.);

- $\quad$ whether to offer psychological or other help to students and staff;

- whether to recommend online exams and in the case of a positive decision, what platform to be used and how to minimize the possibilities of cheating;

- $\quad$ how to adjust the academic calendar;

- and how to organize technical assistance, which it is useful to faculties with a lack of technological education. 
Then, the information, recommendations, and advice for faculties followed:

- the advantages and disadvantages of the software chosen for online teaching and for preparing and sharing materials and assignments, along with tips for scheduling classes, issuing assignments, hosting quizzes, and setting forums or discussions; the pros and cons of asynchronous and synchronous teaching;

- $\quad$ advice for retaining the interest of students and making classes interactive, hints for obtaining their feedback; instructions for dealing with a large group of students;

- $\quad$ advice to be precise in defining and collecting the assignments to avoid misunderstandings;

- $\quad$ reminders to note the presence of students;

- $\quad$ advice on how to conduct office hours or online exams;

- $\quad$ tips and tricks in case of unexpected situations (e.g., low network capacity or other technology failures, or the accidental sharing of private information by voice, camera, or screen);

- $\quad$ external resources that can help both students and teachers in different unpleasant situations;

- $\quad$ advice for teachers and students who are quarantined, self-isolated, or infected.

In most universities, the decisions were publicized in a short time - usually 5-7 days after a particular country had gone on lockdown - in the form of guidelines, instructions, statements, and information (UComenius, 2020; UMiskolc, 2020; ULjubljana, 2020; USDE, 2020; Colleges, 2020; Cohn, 2020). Some universities offered psychological assistance or physical online exercises for maintaining psycho-physiological health (Wang et al., 2020).

A few months after the start of the pandemic, there was a general feeling of anxiety and frustration caused by the COVID-19 danger and consequent lockdowns, curfews, quarantines, self-isolations, and similar restrictions. Additional frustration for teachers who had to continue teaching online stemmed from the fact that "many instructors do not have sufficient training to be able to effectively move courses to an online format" (Kenzig, 2015). However, for the benefit of students and therefore society, many of those instructors rose above their long-lasting professional habits and preferences for in-person teaching and moved to the unknown, namely, an online teaching modality. The education process in general undergoes slow changes; however, this time, the transformation had to be instantaneous.

Teachers likely had doubts about their level of preparedness: Do I have all the technology support that I need? Should I give synchronous or asynchronous instructions? Will I have a good understanding with the collaborator in the course (another teacher, teaching assistant, or technical assistant)? Will the students have home equipment to enable the synchronous online lecture? Can I ask them to turn their camera or microphone on, without disrupting their privacy? Will I prepare my lecture in time? Will I be lost in translation compared to my face-to-face lectures (Kenzig, 2015)? Will I be able to successfully deliver the sensitive parts of the course? Should I weaken the requirements of the course and/or grading criteria in this specific situation? Should I use the software recommended or the one that I have experience with? Should I wait for the end of the lockdown to conduct a particular part of the course or exam (and when will that happen?)? Will I have an appropriate working atmosphere at home, at least while the classes are conducted? Will the advice and recommendations given by university authorities function in reality? Should I learn new multimedia technologies to adjust the course for effective online learning? Should I prepare video lectures? Should I change something in the learning resources? Will I be able to establish a warm, friendly, and relaxing online learning environment? How do I objectively measure students' understanding (e.g., via a test, a quiz, or oral questions) or subjectively measure student satisfaction? Will I receive proper feedback from students? Will they listen to me, or will they set their status to "online" while being in another room? Furthermore, specifically, for STEM courses, teachers likely asked themselves the following questions: Will the students be able to thoroughly follow my ideas and properly understand my words? Should I change my verbal expression style? In my course, should I include parts of university online courses or massive open online courses (MOOCs) offered by a variety of providers, such as edX (Harvard and MIT), Coursera, Udacity, Udemy, and FutureLearn (Ma, 2020). 
Many additional barriers, mainly of a psychological nature, consequently had to be dealt with, but the enormous barriers in the implementation of e-learning still topped the former. Some technical problems encountered were (Ali et al., 2018):

- a lack of technical support, slow internet speeds and high internet traffic in particular time slots,

- technological difficulties faced by students in using e-learning technologies,

- $\quad$ students' reluctance to take responsibility for their own e-learning,

- a sense of isolation due to less face-to-face interaction,

- less diligent work by students because of the relative absence of instructor-learner and learner-learner interaction,

- $\quad$ students' low response to changing to e-learning,

- the inequality of access to the technology itself by all students,

- a lack of effort and support from faculty members in the use of e-learning,

- difficulty in engaging students online, weak IT skills and therefore a lack of technology acceptance by faculty members,

- the high cost of producing high-quality multimedia and learning materials,

- a lack of reliability in online assessment processes,

- $\quad$ and insufficient support of top-level management.

\section{Research method}

This study was identified as qualitative research (Patton, 2002). Thematic analysis was used for data processing and entailed searching across a data set to identify, analyse, and report repeated patterns (Braun et al., 2006; Kiger et al., 2020). This method is used for describing the collected data of all participants in the study and interpreting of codes and creating themes about the attitude of university teachers in online teaching of STEM subjects during COVID-19 lockdown.

\section{Data collection}

The researchers conducted semi-structured online interviews, therefore teachers were allowed the freedom to provide wider, descriptive answers to each of the questions (described in Qu, Dumay, 2011). Before data collection an informed consent document was sent on email to every participant in the research, which ensure voluntary participation, also included description of the research problem and insured confidentiality. After signing the document was returned by every participant to the researchers, and allowing for the questions to be emailed to the participants.

Written answers of the questions were fulfilled by nine participants. They were asked to describe the following:

- How does their faculty or university cope with the forced transition to distance learning due to the COVID-

19 pandemic?

- How do they personally deal with the transition?

- What are their impressions of this situation?

\section{Participants}

Purposive sampling was used for defining the participants. In this qualitative study the interviews were conducted with nine university teachers of STEM courses, males and females regarding their experiences in the unplanned transition to online teaching. The small size sample in this research is justified because qualitative research does not require specific sample sizes (Busetto et al., 2020). The participants are teaching in seven different universities from Brazil, the Czech Republic, Estonia, Hungary, India, North of Macedonia, and Slovakia.

\section{Results}

The researchers have coded the entire data set and have made theme identification. In Table 1 the themes and subthemes from this research are presented. The description and interpretation of the themes that were obtained from the analysis of the interviews are presented. 
Table 1. Data systematization matrix

\begin{tabular}{|c|c|c|c|}
\hline Main theme & Generic themes & Subtheme & Codes \\
\hline \multirow{5}{*}{$\begin{array}{l}\text { University teachers } \\
\text { perception of the online } \\
\text { teaching of STEM } \\
\text { subjects during COVID- } \\
19 \text { lockdown }\end{array}$} & Impact of Covid-19 on & Emotions & Quality of life \\
\hline & & & Emotional well-being \\
\hline & University teachers in & Lectures & Emerging new tools \\
\hline & $\begin{array}{l}\text { the COVID-19 } \\
\text { lockdown }\end{array}$ & Tests & Evaluative process \\
\hline & $\begin{array}{l}\text { Experiences of } \\
\text { organization of the work } \\
\text { at university }\end{array}$ & $\begin{array}{c}\text { Emerging new } \\
\text { technology }\end{array}$ & $\begin{array}{c}\text { Professional } \\
\text { development } \\
\text { Stress from technical } \\
\text { problems }\end{array}$ \\
\hline
\end{tabular}

Quality of life

All of the participants in this study remember the date when everything has changed "based on a decision

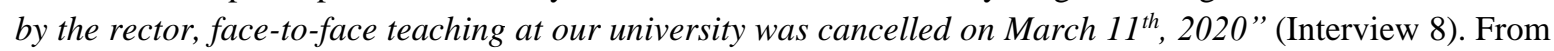
the analyses of the interviews, the Covid-19 pandemic has changed people's lives in every single aspect. The university closures have impact on teachers and students well-being. The life of university teachers was changed and many teachers reported negative psycho-emotional impacts and indicated "however, some teachers have reported higher mental and physical exhaustion in the implementation of online teaching caused by many hours spent at the computer" (Interview 8).

The teachers and students are inserted in digital environment that interrupted the teacher-student interaction, and many of the participants in the study felt the need for social interaction with students, but at the same time noticed the emotional changes in their students in context of whole situation.

"Not all students are pleased with this situation, saying that the in-person form of study has some charm" (Interview 7).

"Several students gave up and postponed their diploma defense until autumn. One student also reported deep depression due to uncertainties. Let us hope that normalizing conditions will allow them to finalize their studies and remember that this spring was an extraordinary one and will not repeat" (Interview 6).

"Some academics miss personal contact and interaction with students. They worry about the gradual transfer of educational activities to the expanding online environment and the associated loss of interpersonal contact and contact with the real world" (Interview 8).

All respondents impatiently await the abating of the Covid-19 crisis yet do not hold out hope that it will be soon.

"Personally, I thought that all this institutional anxiety was unnecessary, as we would soon return to classrooms, but even today, it is difficult to say when that will happen” (Interview 1).

"We are already different from the selves we were in January, and we will surely be different in September. This is how rapidly the world is changing us and changing itself. I could not have predicted this in my wildest dreams" (Interview 2).

"I am seeing all these changes as a wake-up call, reminding us of our limitations, our humanity, our need to be solitary and responsible, and our duties to preserve life and be ready to change. We will change, one way or another" (Interview 7).

\section{Emerging new tools}

All participants in this study, although from different countries, emphasized that they faced a new challenge in their work setting, reacting accordingly to the situation and making wary adaptations to the curriculum, modifying teaching methods and using new tools. Most of the respondents indicate that in their careers they used only traditional lectures that take place in classroom setting, and thus encountered online lectures for the first time. One of the respondents points out "I am a 43-year-old teacher with 20 years" experience in higher education. I consider myself an old-school teacher: For 13 years, I held only traditional courses (content delivered only in writing or orally), and in the past 7 years, web-facilitated face-to-face courses in essence. I had never thought about conducting online classes and exams before March 2020.” (Interview 1). The process of adapting to new online teaching strategies did not go effortlessly, the participants had to respond 
quickly to change and "it has been somewhat difficult to adapt to this new way of lecturing" (Interview 2), also "time was needed to digest all of these novelties" (Interview 1).

"Although in use for many years (some 20 years), this well-established teaching methodology has always been viewed - by either students or institutions - as a secondary option. Now it has become mandatory. Academia was still not ready for the new online lectures. The resources needed for online lectures of a reasonable quality are still non-existent in educational institutions" (Interview 3 ).

"The online teaching format is in its infancy. The standard with minimum requirements for a "distance learning environment" of a reasonable quality is still lacking. This minimum would demand a non-negligible amount of investment to provide a proper set up for "education at distance". MOOCs such as Coursera and MIT OpenCourseWare (Massachusetts Institute of Technology) are at the forefront of this movement. Online lectures, either massive or customized, are here to stay. I would expect this to be an education format to be given more attention, and I would say that institutions adopting a proper combination of both online lectures and in-class lectures are bound to be successful in their role of transmitting and creating knowledge. A lesson to be learned from the current crisis is that "education at distance" is important. Good lectures do not come for free. The means (time, apparatus, and money) required to provide good "Education at Distance" are manifold and must be pursued to achieve optimal results. The current moment has room for improvisation; future moments require the professionalization of this methodology" (Interview 3).

University teachers involved in this research indicated that they have used different platforms, many social-network apps to continue with their work.

"Education was delivered via a large variety of platforms, such as Zoom, Google Scholar, MS Office platforms, and Moodle. Fortunately some years ago, our university set up the MEMOC system, which facilitates the use of massive online educational forms." (Interview 3).

"For the first week of online teaching, I used only Moodle and PowerPoint presentations with voice comments. I uploaded examples and held online consultations via chat in Moodle, which was extremely unfriendly to mathematical symbols" (Interview 3).

\section{Evaluative process}

According to the participants in the sample of this research, when trying to evaluate their students they have showed the greatest concern about evaluative processes. The new context made evaluation a challenging issue.

"The most difficult part seems to be with evaluating students' progress and checking if they cheated on tests. Even on quiz questions that would take a while to read and comprehend, we are seeing students responding in short time spans and getting high grades" (Interview 2).

"I could not imagine holding the exams online, knowing that students are always ahead of teachers by using technology to cheat. Time was needed to digest all of these novelties. I have small groups of students (1020), and only half of them were interested in attending the midterm exam. I could foresee it being easy to follow them on a Zoom video conference (for larger groups, it becomes very difficult). I asked the students (and we practiced a week before the exam) to turn their microphones and cameras on, so that their faces, papers, and calculators would be visible. I prepared the exam questions carefully to minimize the chances of cheating (i.e., to ensure that the questions could not be found anywhere). At most, five randomly chosen students answered the same questions. As the free version of Zoom only allows online meetings for 40 minutes, the exam was held in two 40-minute parts. When a student finished the exam, they sent a photo of their answers and waited until the exam time had elapsed. Only one student was suspected of cheating and was consequently invited to take an oral exam, which they did not pass" (Interview 1).

Most interviewees defined the evaluation process as a problem. Some of the factors that influence it are as follows: an individual's resistance to change, technical limitations and the possibility of student manipulation. Also, online assessment of the students requires the evaluation process to be reworked.

"Problems arose that had been foreseen with the online exam mode: A few students raised the issue that they did not carry the study material from university to their homes; there were network issues; and it was found that the online exam system was not suitable for collaborative evaluations or group projects".

"The next problem arose with the examination period. I planned, as usual, to allow students 90 minutes to solve the exam and upload their answers to Moodle. As I had never tried this form of examination online before, I decided to conduct a trial exam with 23 students. The trial went poorly; the Moodle site crashed, with 
no chance to sign in or upload the solutions. Some experience was gained, and I allowed students to submit exams via email or Moodle” (Interview 7).

The online evaluative process requires a combination of high levels of methodological and IT skills, also offering appropriate platforms developed by universities. Unfortunately some students try to cheat on exams in order to pass. This problem opens new horizons of cooperation for teachers, and makes it necessary for them to share experiences that they might tackle this issue.

"Furthermore, some teachers have pointed out that students in an online form of education do not display as much willingness to fulfil the assigned tasks as in full-time teaching. They often only search for and copy information from the internet, showcasing laziness when using other learning sources, thinking critically, and combining and processing the obtained information. While this is not new information, this fact again implies the need to greatly support and develop these qualities in students from the beginning, regardless of the way in which they are taught" (Interview 8).

"I must add that I am still concerned about the many ways to cheat on online exams" (Interview 1).

Stress from technical problems

New learning formats have increased the work university teachers need to do. On average, they spend more time on education and preparing lectures now than previously. This method requires much more effort and output from them. All those involved in this study used these new methods for "in-class" online learning.

"A lesson to be learned from the current crisis is that "education at distance" is important. Good lectures do not come for free. The means (time, apparatus, and money) required to provide good "Education at Distance" are manifold and must be pursued to achieve optimal results. The current moment has room for improvisation; future moments require the professionalization of this methodology. The need to switch from inperson courses to online courses, albeit abrupt, required a large amount of improvisation. A list of some aspects is given below:

1. The commonly used slide presentations (PowerPoint presentations) are usually much more succinct for an online presentation. Adaptation (almost on the fly) was then required.

2. The need for newly made slides demanded much extra work.

The time to switch from screen sharing mode to the lecturer's or student's image is not fast enough to emulate the dynamics of a live lecture. This is somehow the most annoying stumbling block" (Interview 3).

Different kinds of technical problems were faced by university teachers in this study. Often, they were left to fend for themselves and to overcome difficulties that did not depend directly on them.

"Still, there was a problem of missing sound when a master student tried to defend their presentation on a Linux machine using Teams. It is interesting that it has been the only trouble during online defences. In our department, students were at home or in a distant auditorium and did presentations with simultaneous video provided in Teams. Commission members, supervisors, and opponents participated remotely, if needed. So, I would like to say that the online defence process was also much smoother than expected and can be well practiced in the future. Engaging distant opponents and defence commission members seems much more feasible than earlier.

Education was delivered via a large variety of platforms, such as Zoom, Google Scholar, MS Office platforms, and Moodle. Already some years ago, our university fortunately set up the MEMOC system, which facilitates the use of online massive educational forms" (Interview 7).

"Some teachers had problems with the quality of audio and video transmission. Especially the extensive use of the MS Teams tool, which likely began to be used in a massive way all over the world and made logging in problematic” (Interview 8).

"I noticed few problems during the online educational activities: Students had different computer literacy levels; some students had internet connection problems; internet speeds were slower during some time slots (e.g., on Wednesdays from 9-11 a.m., many institutions held meetings); students who were using smartphones rather than laptops could not input their answers into the test on LMS Moodle and were thus sending me photos of their handwritten solutions by email, which required extra effort to grade” (Interview 9). 


\section{Professional development}

No other crisis ever before has made changes to education so drastic, delegating traditional lecturers to online teaching. Instead of issues of well-being, disturbance of the work-family balance, and work pressure, many of the university teachers in this study considered to have didactical and IT skills to teach online were satisfied. "I can say that I enjoy online teaching and feel that I have grown personally and professionally" (Interview 1), "I took this challenging situation as an opportunity to come out a stronger person and a better professional. I found that it has been challenging for both students and faculty” (Interview 4). The challenges university teachers encountered in the process of shifting to online learning caused them to change. "We are already different from who we were in January, and we will surely be different in September. This is how rapidly the world is changing us and changing itself. I could not have predicted this in my wildest dreams" (Interview 2). As a result of the changes it seems that the "new" formats of education will remain, as a hybrid or online format, and university teachers teaching STEM subjects need to experiment, create and develop different platforms. "New experiences with online studies, efficient teleconferencing skills, and reduced needs for faceto-face meetings are simply bonuses" (Interview 5).

\section{Discussion and Conclusions}

In this article, we presented the views of nine teachers and their personal experiences with the sudden transition to distance learning due to the closure of universities during the COVID-19 pandemic. All of the interviewed teachers teach STEM courses, which require instructor-student and student-student interaction, as well as experiments, measurements, simulations, and deeper mathematical-technical explanations during the lessons.

The three questions in the interview, presented in the previous section, were formulated for the following purposes:

- $\quad$ to understand the institutional rules and adopted actions implemented by faculties and universities in the teaching process, when transitioning to distance learning because of COVID-19;

- $\quad$ to gather personal working experiences and challenges faced in the transition;

- $\quad$ to elicit interviewees' impressions and lessons learnt in this situation.

We will share the most impressive elements of our small-scale introductory research, which we plan to expand in the future with a larger sample of case studies (i.e., interviews). One of the most important elements in the sudden transition to e-learning was the choice of software tools, platforms, and applications for achieving as appropriate an e-learning environment as possible. Numerous tools were recommended by the universities, and some of them were the personal choice of the individual teacher: MS Teams, LMS Moodle for teaching and testing, LMS UNIFOR, OneNote or OneDrive, SharePoint, the Edu NXT platform, Whiteboard, and MOOCs, among many others. Some universities have specifically recommended the Zoom platform, whereas others have forbidden it due to security reasons.

According to interviews it was obvious that university teachers experienced many changes. Starting with the changes in their well-being and disturbed teacher-student relationships, they were forced to modify their didactical methods, to shift from traditional face-to-face mode to a new online format. Regarding lessons, assessment processes was given special attention. Many university teachers encountered mountainous problems, the main reason some teachers reported frustration and a sense of being overloaded with information. However, they indicated professional development and satisfaction with themselves for overcoming the obstacles.

The general opinion of teachers is that online classes do not completely substitute live classes. However, the investment of double or triple the effort has ensured the quality of classes. One of our interviewees compared the situation to "changing a tire with the car in motion". A few obstacles, typical of the transition to distance learning under normal circumstances, were intensified in this specific situation: a lack of technological experience among students and teachers, students' reluctance to take responsibility for their own e-learning, a sense of isolation due to less face-to-face interaction, less diligent work of students because of the relative absence of instructor-learner and learner-learner interaction, the high cost of producing high-quality multimedia and learning materials, and the lack of reliability of the online assessment process. Additionally, the teachers have noted improvisations and manipulations from the students' side. Furthermore, the mental and physical exhaustion of teachers is one of the most important issues highlighted in the interviews. Another concern reported by the teachers is cheating on tests: Students are usually ahead of their teachers in inventing ways to 
cheat; however, cheating might be reduced when exams are conducted exclusively orally or in combination with written exams. To this end, some universities partially opened their buildings from June and organized inperson examinations for a restricted number of students.

Positive impressions of this period were used to keep teachers' motivation and morale high. Some of the interviews indicate that the teachers feel satisfied with developing their digital, software, and personal skills, and hence their personal and professional growth. Personal skills are mainly related to successful teaching by teleconferencing, a skill that requires concise and optimized oral and written expression. Some new opportunities for teachers also emerged, such as following other teachers' lectures or being practical by sharing teaching obligations among colleagues. Moreover, teachers had an opportunity to separate activities that can be successfully performed without the need for physical presence from those that cannot work without it, a step that may prove helpful in future international activities and cooperation. However, most of them agree that for lecturing, physical presence is irreplaceable.

COVID-19 is still present in the world, aggressive in every country. Depending on the decisions made by the ministries of education and by universities, distant learning might continue in the coming years. For example, on May 20th, 2020, the University of Cambridge announced the suspension of mass lectures in person for the 2020/21 academic year (UCambridge, 2020). Not only because of the COVID-19 lockdowns, but also because of the high involvement of technology in education, the future education process appears to be gradually developing into a balanced combination of distance and face-to-face formats. The presented research can be used as a starting point for developing surveys, questionnaires, or interviews about experiences in forced distant education among larger samples of not only teachers but also educational providers' representatives and students.

The research can be developed in the following directions: examining teachers' levels of satisfaction with the reactions of ministries and universities; identifying positive and negative issues detected while teaching online, along with ideas for stimulating the positive issues and overcoming the negative ones; understanding the intensity of the sense of isolation; assessing the change in the quality of teacher-student relationships; and determining strategies for increasing students' motivation during the altered teaching process. All of these listed research directions can also be analysed from students' viewpoints. Furthermore, to undertake a comparative study between the various education providers and institutions, administration and technical support persons from those institutions can be interviewed to understand the decisions made regarding software, time management, help offered to students and teachers, and specific decisions made motivated by the location or mentality of locals. The findings will assist educational providers in foreseeing and eliminating the possible problems of teachers and students when establishing an online educational environment, regardless of whether the situation is urgent or planned (Koreňová, 2017).

Funding: This research received no external funding.

Acknowledgments: We thank seven faculty members who shared their personal experiences in Section 3 of this paper: 1. Costa Max Henrique Machado, School of Electrical and Computer Engineering, University of Campinas, Campinas, Brazil;

2. Dhaka Arvind, Faculty of Computer and Communication Engineering, Manipal University Jaipur, Jaipur, India;

3. Finamore Weiler Alves, Faculty of Engineering, Instituto Technológico de Aeronáutica (ITA), São José dos Campos, Brazil;

4. Körtesi Peter, University of Miskolc, Faculty of Materials Science and Engineering, Hungary;

5. Kuusik Alar, School of IT, Tallin University of Technology, Tallin, Estonia;

6. Nocar David, Faculty of Education, Palacký University in Olomouc, Czech Republic;

7. Tkacik Stefan, Faculty of Education, Catholic University in Ruzomberok, Slovakia.

The authors of the paper wish to acknowledge the valuable contribution and support of grant VEGA 1/0079/19 "Analysis of critical points in school mathematics and identification of factors influencing pupils' attitude to mathematics" and CEEPUS Network CIII-HU-028-14-2021 "Active Methods in Teaching and Learning Mathematics and Informatics".

We thank Johnathan Dabney for the English language editing.

\section{References}

Allen, I. E., \& Seaman, J. (2016). „Online Report Card: Tracking Online Education in the United States”. Retrieved April 1, 2021, from https://files.eric.ed.gov/fulltext/ED572777.pdf 
Ali, S., Uppal, M., \& Gulliver, S. (2018). A conceptual framework highlighting e-learning implementation barriers. Information Technology \& People, 31(1), 156-180.

Bhuasiri, W., Xaymoungkhoun, O., Zo, H., Rho, J.J., \& Ciganek, A.P. (2012). Critical success factors for e-learning in developing countries: A comparative analysis between ICT experts and faculty. Computers \& Education, 58(2), 843855.

Braun, V., \& Clarke, V. (2006). Using thematic analysis in psychology. Qualitative Research in Psychology, 3(2), $77-101$. https://doi.org/10.1191/1478088706qp063o

Busetto, L., Wick, W., \& Gumbinger, C. (2020). How to use and assess qualitative research methods. Neurol. Res. Pract. 2, 14 https://doi.org/10.1186/s42466-020-00059-z

Cohn, J., J., \& Seltzer, B. (2020). "Teaching Effectively During Times of Disruption, for SIS and PWR". https://docs.google.com/document/d/1ccsudB2vwZ_GJYoKlFzGbtnmftGcXwCIwxzf-jkkoCU/edit

Crawley, F.E., Fewell, M.D., \& Sugar, W.A. (2009). Researcher and Researched: The Phenomenology of Change from Face-to-Face to Online Instruction. Quarterly Review of Distance Education, 10(2), 165-176.

Colleges. (2020). "Colleges and universities closed/migrating online for COVID-19 - crowed sourced spreadsheet". Retrieved April 1, 2021, from

https://docs.google.com/spreadsheets/d/19wJZekxpewDQmApULkvZRBpBwcnd5gZIZF2SEU2WQD8/htmlview\#g id $=0$

Elearning. (2020). Retrieved April 1, 2021, from https://elearning.uni-miskolc.hu/

EVML. (2020). Retrieved April 1, 2021, from https://www.uni-miskolc.hu/evml/

HMTM. (2020). „Conference History of Mathematics and Teaching of Mathematics”. Retrieved April 05, 2020, from www.uni-miskolc.hu/hmtm

Kebritchi, M., Lipschuetz, A., \& Santiague, L. (2017). Issues and Challenges for Teaching Successful Online Courses in Higher Education: A Literature Review. Journal of Educational Technology Systems, 46(1), 4-29.

Kelly, B., Phipps, L., \& Swift, E. (2004). Developing a Holistic Approach for E-Learning Accessibility. Canadian Journal of Learning and Technology, 30(3), 1-14.

Kenzig, M. J. (2015). Lost in Translation: Adapting a Face-to-Face Course Into an Online Learning Experience. Health Promot Pract. 16(5), 625-628. https://doi.org/10.1177/1524839915588295

Kiger, M. E., \& Varpio, L. (2020). Thematic analysis of qualitative data: AMEE Guide No. 131, Medical Teacher, 1-9. https://doi.org/10.1080/0142159X.2020.1755030

Kommers, P. (2019). Educational Technologies for E-learning and STEM Education. In E. Trybulska-Smyrnova (Eds.), Elearning and STEM Education. Katowice-Cieszyn: University of Silesia in Katowice, Faculty of Arts and Education Sciences in Cieszyn. pp. 35-49.

Koreňová, L. (2017). GeoGebra in Teaching of Primary School Mathematics. International Journal for Technology in Mathematics Education, 24(3),155-160.

Ma, R., \& Mendez, M. C. (2020). Free online Learning Due to Coronavirus (Updated Continiously). Retrieved April 18, 2020, from https://www.classcentral.com/report/free-online-learning-coronavirus/

Nat-resp. (2020). Wikipedia: National responses to the COVID-19 pandemic. Retrieved April 18, 2020, from https://en.wikipedia.org/wiki/National_responses_to_the_COVID-19_pandemic

NCES. (2020). National Center for Education Statistics. Retrieved April 18, 2020, from https://nces.ed.gov/fastfacts/display.asp?id=80

Q. Qu, S., \& Dumay, J. (2011). The qualitative research interview. Qualitative Research in Accounting \& Management, 8(3), 238-264.

Renes, S.L., \& Strange, A.T. (2011). Using Technology to Enhance Higher Education. Innovative Higher Education, 36 , 203-213.

Stando, J., Sakowicz, B., Mazur, P., \& Kusztelak, G. (2012). Fault tolerant on-line examining engine for primary and secondary schools. In 2012 International Conference on E-Learning and E-Technologies in Education (ICEEE). 1316, doi: 10.1109/ICeLeTE.2012.6333414

UCambridge. (2020). University of Cambridge, A statement from Professor Graham Virgo, Senior Pro-Vice-Chancellor (Education) regarding the academic year 2020-21. Retrieved April 18, 2020, from https://www.cam.ac.uk/coronavirus/news/update-from-the-senior-pro-vice-chancellor-education-regarding-theacademic-year-2020-21

UComenius. (2020). Comenius University of Bratislava, Coronavirus: Current Information. Retrieved April 18, 2020, from https://uniba.sk/en/comenius-university-news/coronavirus/

ULjubljana. (2020). University of Ljubljana, UL and Coronavirus. Retrieved April 18, 2020, from https://www.unilj.si/ul_and_coronavirus/ 
UMiskolc. (2020). University of Miskolc, All the Official Statements of the University of Miskolc Regarding Corona Virus can be Found Here. Retrieved April 18, 2020, from

https://www.uni-miskolc.hu/hirek/2265/all_the_official_statements_of_the_university_of_miskolc_regarding_ coronavirus_can_be_found_here

USDE. (2020). Guidance for interruptions of study related to Coronavirus (COVID-19), issued by Office of Postsecondary Education, U.S. Department of Education (March 05, 2020 and update from April 05, 2020). Retrieved April 05, 2020 , from https://ifap.ed.gov/electronic-announcements/030520Guidance4interruptionsrelated2CoronavirusCOVID19

Wang, C., Cheng, Z., Yue, X.-G., \& McAleer, M. (2020). Risk Management of COVID-19 by Universities in China. J. Risk Financial Manag.

Zhang, D., Zhao, J. L., Zhou, L., \& Nunamaker, J. F. (2004). Can e-learning replace classroom learning? Communications of the ACM, 47(5), 75-79. https://doi.org/10.1145/986213.986216

Zoom. (2020). Retrieved April 05, 2020, from https://zive.aktuality.sk/clanok/146384/dalsi-problem-pre-zoom-s-jehouctami-sa-veselo-obchoduje/

(C) 2021 by the authors. Submitted for possible open access publication under the terms and conditions of the Creative Commons Attribution (CC BY) license (http://creativecommons.org/licenses/by/4.0/). 